\title{
Кристаллическая структура и термоэлектрические свойства тонких слоев $\mathrm{MnSi}_{x}$
}

\author{
(C) И.В. Ерофеева, М.В. Дорохин, В.П. Лесников, А.В. Здоровейщев, А.В. Кудрин, \\ Д.А. Павлов, Ю.В. УСов
}

Научно-исследовательский фризико-технический институт

Нижегородского государственного университета им. Н.И. Лобачевского,

603950 Нижний Новгород, Россия

E-mail: irfeya@mail.ru

(Получена 27 апреля 2016 г. Принята к печати 10 мая 2016 г.)

Методом импульсного лазерного осаждения получены тонкие (25 нм) пленки $\mathrm{Si}_{1-x} \mathrm{Mn}_{x}$ на $\mathrm{Si}(100)$. По данным высокоразрешающей просвечивающей электронной микроскопии, пленки представляют собой нанотекстурированный кристалл химически однородного состава. Исследованы температурные зависимости удельного сопротивления и термоэдс в интервале $300-500 \mathrm{~K}$, рассчитана температурная зависимость коэффициента Зеебека и фактора мощности.

\section{1. Введение}

Получение наноразмерных слоев термоэлектрических материалов является одной из современных тенденций технологии термоэлектрических преобразователей энергии [1]. Известны данные, описывающие получение и исследование наноструктур на основе различных полупроводниковых и металлических материалов (например, $\mathrm{Bi}_{2} \mathrm{Te}_{3}$ [1], $\mathrm{Mg}_{2} \mathrm{Si}_{0.4} \mathrm{Sn}_{0.6}$ [2], $\mathrm{In}_{x} \mathrm{Ce}_{y} \mathrm{Co}_{4} \mathrm{Sb}_{12}$ [3], соединения Ві и Те $[4,5])$.

Выбор материалов основывается на требованиях к величине эффективности термоэлектрического преобразователя, а также к диапазону рабочих температур (каждый из перечисленных материалов характеризуется наибольшей эффективностью в сравнительно узком температурном интервале). Перспективным материалом для интервала 400-600 K считается силицид марганца со сверхструктурным упорядочением [6]. Можно отметить работы по созданию наноструктур на основе объемного силицида марганца [7]. Ожидается, что использование наноструктур на основе $\mathrm{MnSi}_{x}$ в качестве элементов термоэлектрических преобразователей позволит повысить основные характеристики прибора до уровня наилучших структур [1-4].

Целью настоящей работы - формирование тонких нанометровых слоев $\mathrm{MnSi}_{x}$ методом импульсного лазерного осаждения (ИЛО) на различных подложках при разных температурах роста и анализ структурных и электрических свойств полученных слоев.

\section{2. Методика эксперимента}

Формирование слоев силицида марганца осуществлялось в установке ИЛО в вакууме путем поочередного распыления Si (КДБ-12) и $\mathrm{Mn}$ мишеней. Состав слоя задавался соотношением времен распыления мишеней кремния и $\mathrm{Mn}$.

В работе проведена серия ростовых экспериментов по формированию указанных слоев на подложках $\mathrm{Si}(100)$
(КДБ-12) и полуизолирующего GaAs (100). Толщина слоев составляла 20-30 нм. Температура осаждения слоев силицида марганца в эксперименте варьировалась в пределах $250-450^{\circ} \mathrm{C}$. Подобный диапазон температур является оптимальным для формирования структур со сверхструктурным упорядочением, как было получено в предшествующих опытах [2]. В тех же условиях была сформирована многослойная структура, представляющая собой чередующиеся слои $\mathrm{Mn}$ и $\mathrm{Si}$. Основные варьируемые параметры структур представлены в табл. 1.

Для изучения кристаллического совершенства структуры полученных слоев использовался высокоразрешающий просвечивающий электронный микроскоп (BРПЭМ) JЕМ-2100F. Однородность химического состава слоев определялась методом энергодисперсионной рентгеновской спектроскопии (ЭДРС) посредством детектоpa $X$-max компании Oxford Instruments, являющегося элементом ВРПЭМ. Дифракционная картина области контакта $\mathrm{MnSi}_{x} / \mathrm{Si}$ получена с применением ВРПЭМ в режиме микродифракции.

Слоевое сопротивление, концентрация и тип носителей заряда определены в диапазоне температур 300-600 K с использованием стандартной методики измерения сопротивления и эффекта Холла на постоянном токе в геометрии Ван-дер Пау. Для изменения эффекта Холла использовалось постоянное магнитное поле напряженностью 5170 Э.

Измерение термоэдс проводилось в вакууме $10^{-3}$ Торр. Горячий конец образца располагался на графитовой пластине, температура которой устанавливалась и поддерживалась постоянной $( \pm 1 \mathrm{~K})$ в диапазоне $300-600 \mathrm{~K}$. Под второй (холодный) конец образца подкладывался кусок слюды, отделяя его от разогретой графитовой пластины и создавая разность температур $20-40^{\circ} \mathrm{C}$.

В работе выполнялись измерения термоэдс между горячим и холодным концом образца $(\Delta U)$. На основании полученных данных рассчитывались значения 
Таблица 1. Параметры слоев силицида марганца, сформированных методом ИЛО

\begin{tabular}{l|c|c|c|c}
\hline $\begin{array}{c}\text { № } \\
\text { образца }\end{array}$ & $\begin{array}{c}\text { Время осаждения, с/ } \\
\text { толщина слоя, нм }\end{array}$ & $\begin{array}{c}\text { Температура } \\
\text { осаждения, }{ }^{\circ} \mathrm{C}\end{array}$ & Подложка & $\begin{array}{c}\text { Примерный } \\
\text { состав пленки }\end{array}$ \\
\hline S 68-4 & $1800 / 20$ & 250 & $\mathrm{Si}(100)$ & $\mathrm{Si}_{0.55} \mathrm{Mn}_{0.45}^{* *}$ \\
$\mathrm{~S}$ 59-5 & $1800 / 20$ & 300 & $\mathrm{Si}(100)$ & $\mathrm{Si}_{0.55} \mathrm{Mn}_{0.45}$ \\
$\mathrm{~S}$ 60-5 & $1800 / 20$ & 400 & $\mathrm{Si}(100)$ & $\mathrm{Si}_{0.55} \mathrm{Mn}_{0.45}$ \\
S 64-8 & $9000 / 100$ & 450 & $\mathrm{Si}(100)$ & $\mathrm{Si} / \mathrm{Mn}$ \\
& & & & многослойная \\
G 59-5 & $1800 / 20$ & 300 & $\mathrm{GaAs}(100)$ & $\mathrm{Si}_{0.55} \mathrm{Mn}_{0.45}$ \\
G 60-5 & $1800 / 20$ & 400 & $\mathrm{GaAs}(100)$ & $\mathrm{Si}_{0.55} \mathrm{Mn}_{0.45}$
\end{tabular}

Примечание. ${ }^{*}$ - Номинальная толщина слоя, ${ }^{* *}-$ Состав задается соотношением времен распыления.

коэффициента Зеебека по формуле

$$
a=\Delta U / \Delta T,
$$

где $a-$ коэффициент Зеебека, $\Delta T-$ разница температур между горячим и холодным концами. Также рассчитывалось значение фактора мощности по формуле

$$
p=a^{2} \cdot \sigma
$$

где $p-$ фактор мощности, $\sigma-$ проводимость.

\section{3. Экспериментальные результаты и обсуждение}

\section{1. Кристаллическая структура и состав наноразмерных слоев SiMn}

Исследования, выполненные на электронном микроскопе, показали, что пленки представляют собой нанотекстурированный кристалл. На рис. 1 представлена дифракционная картина исследованных слоев, полученная с использованием ВРПЭМ в режиме микродифракции. Крупные рефлексы на рис. 1 отвечают дифракции электронов на монокристалле кремния (подложка), точечные рефлексы, ложащиеся на кольцо, - характерная картина электронной дифракции (ЭД) для поликристаллов с ориентированными под разными углами

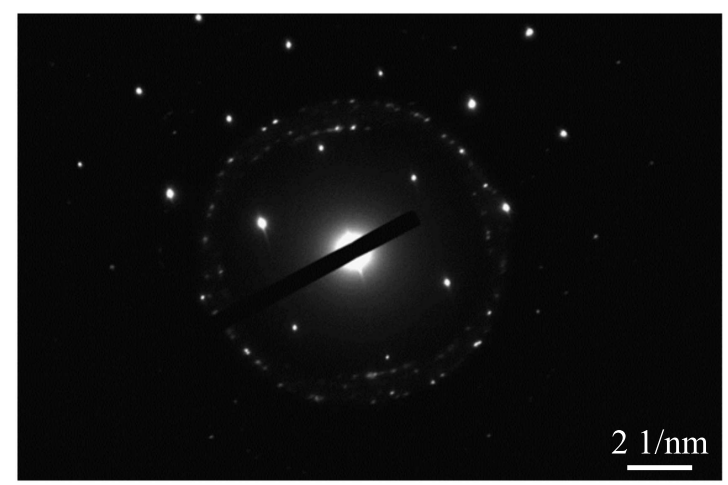

Рис. 1. Картина электронной микродифракции $\mathrm{MnSi}_{x}$ на монокристалле $\mathrm{Si}$ (S 68-4 в табл. 1).

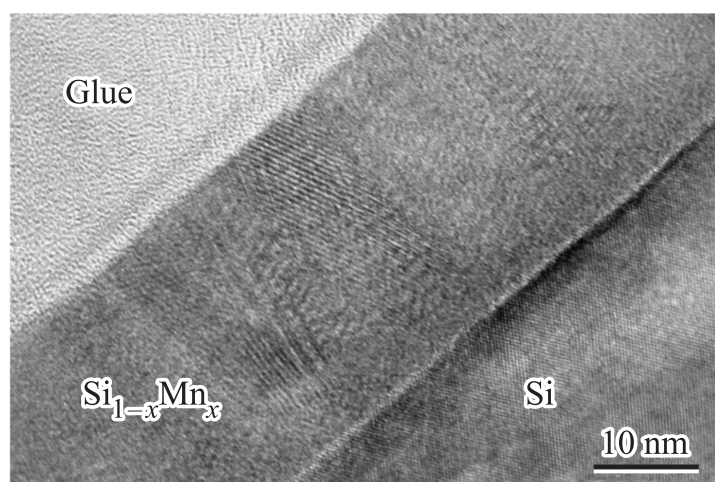

Рис. 2. Электронно-микроскопическое изображение среза структуры слоя $\mathrm{MnSi}_{x}$ на подложке $\mathrm{Si}$, полученное на ВРПЭМ (образец S 68-4 в табл. 1).

отдельными кристаллитами (слой $\mathrm{MnSi}_{x}$ ). Электронной дифракции можно поставить в соответствие электронномикроскопическое изображение высокого разрешения поперечного среза структуры S68-4, показанное на рис. 2. Видно, что слой $\mathrm{MnSi}_{x}$ состоит из наноразмерных монокристаллических блоков с характерным размером нанокристаллитов $\sim 10$ нм. Подобная ультрамелкозернистая текстура обеспечивает большое число границ внутри слоя силицида марганца, что, с одной стороны, увеличивает рассеяние носителей заряда и может уменьшать электропроводность, но с другой это может значительно уменьшать теплопроводность $\varkappa$, повышая рассеяние фононов на границах блоков с разным направлением роста [6] и этим увеличивая термоэлектрическую эффективность $Z=a^{2} \cdot \sigma / \varkappa$. Отметим, что при создании термоэлектрических материалов с высоким значением относительной термоэлектрической добротности $(Z T)$, получаемым за счет низкой теплопроводности материалов, стараются подобрать условия формирования и состав такими, чтобы материал имел наноразмерные включения, например, второй фазы химического состава, либо вводят их специально (например, выращивают квантовые точки) [6]. В нашем случае структура, содержащая рассеивающие нанообъ- 
Таблица 2. Результаты электрических измерений слоев силицида марганца. Измерения выполнены в диапазоне температур $300-500 \mathrm{~K}$

\begin{tabular}{c|c|c|c|c}
\hline $\begin{array}{c}\text { № } \\
\text { образца }\end{array}$ & $\begin{array}{c}\text { Температура } \\
\text { осаждения, }{ }^{\circ} \mathrm{C}\end{array}$ & $\begin{array}{c}\text { Подвижность, } \\
\mathrm{cm}^{2} / \mathrm{B} \cdot \mathrm{c}\end{array}$ & $\begin{array}{c}\text { Слоевая } \\
\text { концентрация }\left(\mathrm{cm}^{-2}\right)\end{array}$ & $\begin{array}{c}\text { Тип } \\
\text { проводимости }\end{array}$ \\
\hline S 68-4 & 250 & $2-8$ & $(1-5) \cdot 10^{16}$ & Дырочная \\
S 59-5 & 300 & $1-5$ & $(0.5-30) \cdot 10^{16}$ & Ð \\
S 60-5 & 400 & $5-60$ & $(1-4) \cdot 10^{15}$ & Электронная \\
S 64-8 & 450 & $5-20$ & $(1-3) \cdot 10^{14}$ & Дырочная \\
G 59-5 & 300 & $1-5$ & $(0.5-20) \cdot 10^{16}$ & $\gg$
\end{tabular}

екты, получается автоматически в процессе роста, при этом состав пленки имеет только одну фазу по химическому составу. Однородность химического состава в слое $\mathrm{MnSi}_{x}$ подтверждена методом ЭДРС. В случае отсутствия в слое неоднородностей химического состава на создание термоэдс работает весь объем материала.

Определенная по данным ВРПЭМ толщина исследуемых структур составляет $\sim 25$ нм.

Повышение температуры выращивания силицида марганца приводит к повышению кристаллического качества структур, как следует из исследований, выполненных в работах $[1,2,7]$ для серии структур с параметрами, аналогичными использованным в настоящей работе. В цитированных работах было показано, что слои силицида марганца, сформированные на подложке GaAs при температуре $300^{\circ} \mathrm{C}$, представляют собой эпитаксиальную структуру с большим количеством двумерных дефектов (границ зерен). Аналогичные условия были установлены для формирования слоев, исследованных в настоящей работе.

\section{2. Электротранспортные свойства}

В настоящей работе получены температурные зависимости (от 300 до $600 \mathrm{~K}$ ) электротранспортных свойств слоев силицида марганца, осажденных на подложки кремния (КДБ-12) и полуизолирующего GaAs (АГЧП100). Результаты измерений температурной зависимости сопротивления для слоев силицида марганца, отличающихся температурой формирования или типом подложки представлены на рис. 3. Выявлено существенное изменение свойств слоев при варьировании температуры формирования, а именно изменение типа проводимости (с дырочного на электронный) и характера проводимости (с полупроводникового на металлический; для металлического характера проводимости характерно повышение сопротивления с ростом температуры, для полупроводникового - наоборот) (табл. 2),

Для слоя, сформированного при температуре $250^{\circ} \mathrm{C}$, зарегистрирована дырочная проводимость, и с ростом температуры сопротивление несколько уменьшается. Значение слоевой концентрации дырок варьируется в пределах $(1-5) \cdot 10^{16} \mathrm{~cm}^{-2}$, величина подвижности - в пределах 2-8 cм²/B·c, такое низкое значение соответствует дырочной проводимости в полупроводнике с высокой концентрацией дефектов (по данным электронографических исследований, рассматриваемые слои $\mathrm{MnSi}_{x}$ являются поликристаллами).

При повышении температуры осаждения до $300^{\circ} \mathrm{C}$ для слоев силицида марганца регистрируется дырочная проводимость (кривые 1 и 2 на рис. 3 ) и наблюдается увеличение концентрации носителей до $(0.5-20) \cdot 10^{17} \mathrm{~cm}^{-2}$ табл. 2). Значение подвижности лежит в тех же пределах, что и для случая слоя, сформированного при $250^{\circ} \mathrm{C}$.

Незначительный рост слоевого сопротивления $\left(\sim 10 \% R_{S}\right)$ на участке $250-500 \mathrm{~K}$ сменяется более заметным падением при температуре измерений выше $500 \mathrm{~K}$ (светлые квадраты на рис. 3). Подобное немонотонное поведение $R_{s}(T)$ может быть связано с фазовым переходом парамагнетик/ферромагнетик, которое выражается в наличии незначительного максимума $R_{S}(T)$ в области точки Кюри. В [1] показана возможность лазерного синтеза тонких эпитаксиальных слоев $\mathrm{SiMn}_{x}$ с точкой Кюри, существенно выше комнатной температуры.

Повышение температуры осаждения до $400^{\circ} \mathrm{C}$ приводит к изменению типа проводимости силицида мар-

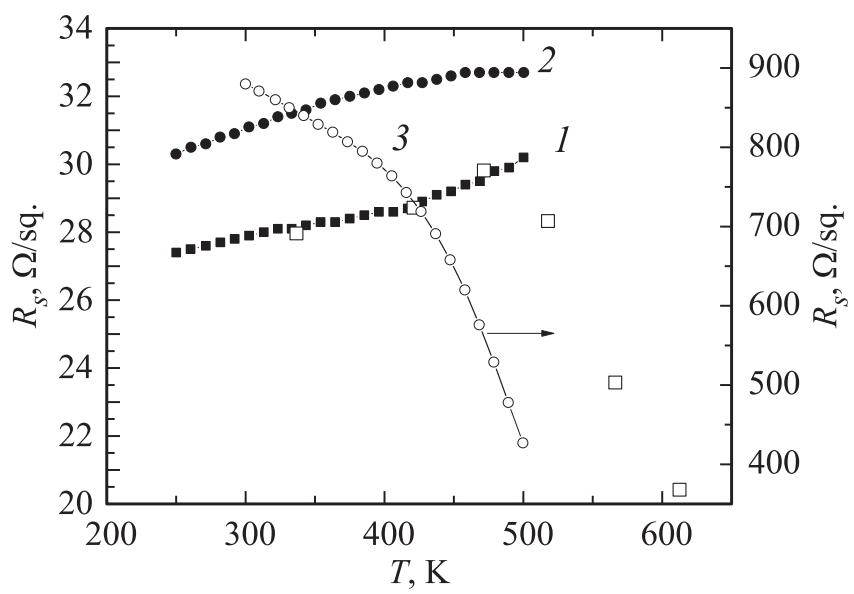

Рис. 3. Температурные зависимости слоевого сопротивления пленок $\mathrm{MnSi}_{x}$, осажденных на поверхность $\mathrm{Si}$ (кривая 1) и GaAs (кривая 2) при температуре роста $300^{\circ} \mathrm{C}$ и при температуре $400^{\circ} \mathrm{C}$ на поверхности $\mathrm{Si}$ (кривая 3). Светлые квадраты $R_{s}(T)$ для $\mathrm{MnSi}_{x}$ на $\mathrm{Si}$ при температуре роста $300^{\circ} \mathrm{C}$. 


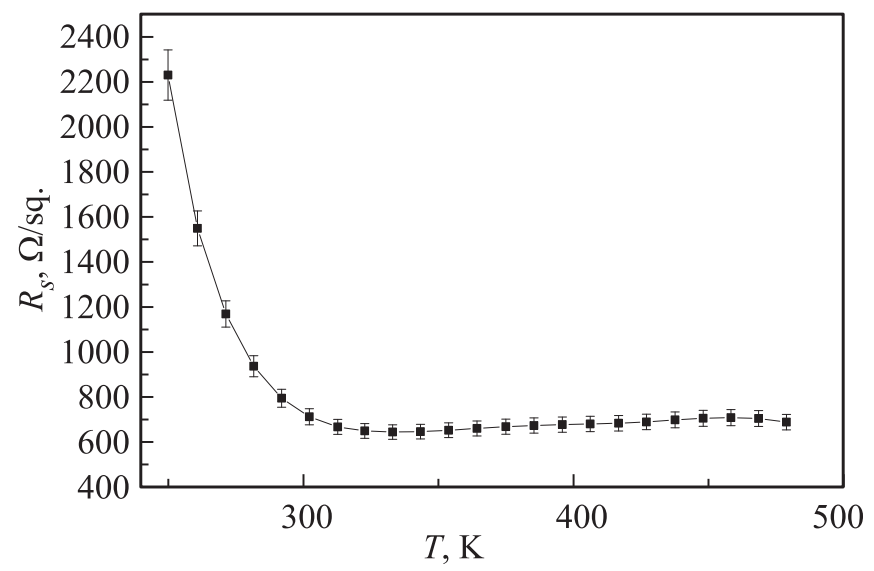

Рис. 4. Температурная зависимость слоевого сопротивления многослойной структуры $\mathrm{Si} / \mathrm{Mn}$, осажденной на поверхность $\mathrm{Si}$.

ганца на электронный, что следует из изменения знака постоянной Холла. Величина сопротивления, аналогично случаю $250^{\circ} \mathrm{C}$, уменьшается с ростом температуры измерений (кривая 3 на рис. 3), что соответствует полупроводниковому характеру проводимости. Неметаллический характер проводимости подтверждается также меньшим значением слоевой концентрации носителей $\left((1-4) \cdot 10^{15} \mathrm{~cm}^{-2}\right.$ табл. 2).

Температурные зависимости сопротивления слоев $\mathrm{MnSi}_{x}$, сформированных на подложках $\mathrm{Si}$ и $\mathrm{GaAs}$, представлены на рис. 3 (кривые 1 и 2 соответственно, температура осаждения $300^{\circ} \mathrm{C}$ ). Вид зависимости качественно совпадает для обоих случаев, несколько отличается лишь величина слоевого сопротивления (в пределах $10 \%$ ), что можно объяснить влиянием подложки на структурное совершенство осаждаемого слоя, от которого, в свою очередь, зависит величина слоевого сопротивления.

Для многослойной структуры $\mathrm{Si} / \mathrm{Mn} / \mathrm{Si}$ (S64-8 в табл. 1) получена немонотонная зависимость сопротивления от температуры, которую, вероятно, также можно связать с фазовым переходом парамагнетик/ферромагнетик при температуре выше комнатной (рис. 4). Значения концентрации $(1-3) \cdot 10^{14} \mathrm{~cm}^{-2}$ соответствуют случаю полупроводникового характера проводимости в слое.

Зарегистрированные изменения электрических свойств слоев силицида марганца (рис. 3) могут быть объяснены влиянием атомной и кристаллической структуры силицида марганца на его свойства. Так, величина проводимости зависит от степени кристаллического совершенства слоев (последнее оказывает влияние на подвижность носителей) [8]. Чем выше степень кристаллического совершенства, тем ниже сопротивление полупроводников. Концентрация носителей в слое $\mathrm{MnSi}_{x}$ определяется степенью компенсации дырок дефектными центрами различной природы. Для силицида марганца в качестве дефектных центров могут выступать границы зерен или атомы Mn в положении междоузлия (являющиеся двойным донором) $[9,10]$. Наличие подобного типа дефектов можно предполагать в структурах, сформированных при $400^{\circ} \mathrm{C}$, для которых зарегистрирована электронная проводимость.

Таким образом, исследования показали, что варьирование температуры осаждения позволяет управлять типом (электронный/дырочный) проводимости слоев $\mathrm{MnSi}_{x}$. Физическая природа указанного явления связана c особенностями атомной (связанной с вхождением примесей) и кристаллической (связанной с упорядочением) структуры слоев. Полученные закономерности делают примененный метод формирования силицида марганца перспективным при создании термоэлектрических преобразователей энергии, поскольку изменение температуры осаждения позволяет в широких пределах варьировать электрические параметры слоев.

\section{3. Термоэлектрические свойства}

Для исследованных структур получены температурные зависимости коэффициента Зеебека в диапазоне температур 300-500 K в зависимости от основных варьируемых параметров. Результаты представлены на рис. 5 и 6.

Качественно температурные зависимости как коэффициента Зеебека, так и фактора мощности подобны для всех структур, содержащих слой $\mathrm{MnSi}_{x}$ (рис. 5,6), и согласуются с литературными данными, описывающими характеристики высших силицидов марганца [11]. С ростом температуры в диапазоне $300-500 \mathrm{~K}$ имеет место монотонное увеличение фактора мощности. Отметим обратный знак коэффициента Зеебека, полученный для структуры $\mathrm{S} 60-5$, со слоем $\mathrm{MnSi}_{x}$, сформированным при температуре $400^{\circ} \mathrm{C}$ (рис. 6). Изменение знака связывается с электронным типом проводимости слоя $\mathrm{MnSi}_{x}$

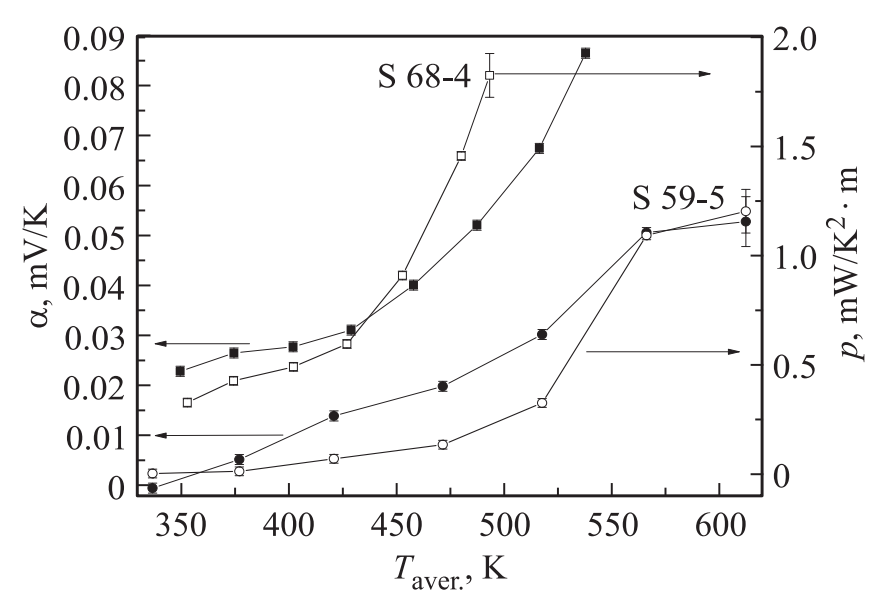

Рис. 5. Зависимость коэффициента Зеебека (закрытые значки) и фактора мощности (открытые значки) от средней температуры между горячим и холодным концами образца для образцов, сформированных при различных температурах роста (S68-4 $\left.T_{\text {роста }}=250^{\circ} \mathrm{C}, \mathrm{S} 59-5 T_{\text {роста }}=300^{\circ} \mathrm{C}\right)$. 


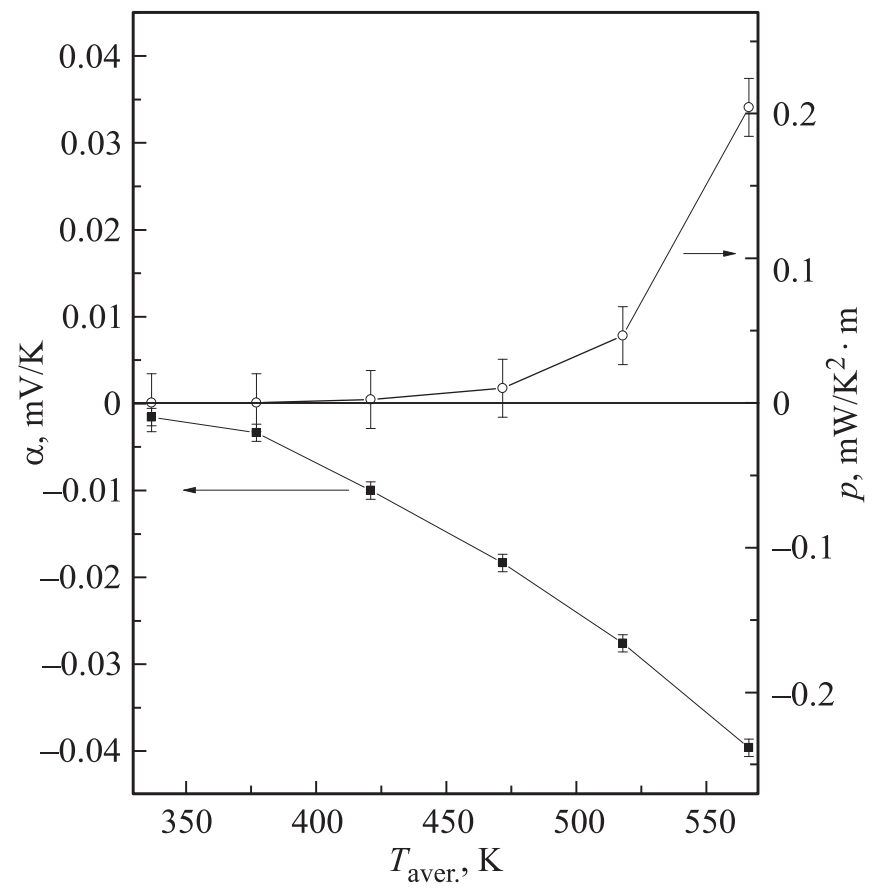

Рис. 6. Зависимость коэффициента Зеебека (сплошная линия) и фактора мощности (с символами) от средней температуры между горячим и холодным концами образца для образца, сформированного при $T=400^{\circ} \mathrm{C}$ (образец $\mathrm{S} 60-5$ ).

(для всех остальных случаев зарегистрирован дырочный тип проводимости, как показано в табл. 2). Зависимость знака термоэдс и коэффициента Зеебека от типа проводимости является фундаментальным свойством эффекта в полупроводниках [12]. Зарегистрированный „отрицательный“ знак коэффициента Зеебека для многослойной структуры $\mathrm{Si} / \mathrm{Mn} / \mathrm{Si}$ для области низких температур также связывается с изменением типа проводимости в структуре по мере нагрева. Наибольшие значения фактора мощности (рис. 5) были получены для структур S 68-4 и $\mathrm{S} 59-5$ и составили 1.8 и $1.2 \mathrm{MBT} / \mathrm{K}^{2}$ м соответственно, что лежит в диапазоне наилучших значений для термоэлементов согласно данным работы [13]. Повышение температуры формирования приводит к значительному уменьшению фактора мощности полученного для структуры с полупроводниковым характером проводимости, что согласуется с работой [14], в которой показано, что наибольшие значения фактора мощности следует ожидать в сильнолегированных полупроводниковых структурах, а переход к металлической проводимости приводит к снижению указанного параметра.

\section{4. Заключение}

Таким образом, в работе показано, что метод импульсного лазерного осаждения может применяться для формирования слоев термоэлектрических материалов с ультрамелкозернистой поликристаллической струк- турой. Структура и однородность слоев зависят от температуры формирования. Оптимальным диапазоном для создания однородных поликристаллических слоев с большим количеством границ зерен представляется температура в диапазоне $250-300^{\circ} \mathrm{C}$.

Приведенные результаты термоэлектрических параметров, хоть и ниже максимальных известных значений, но были получены для слоев силицида марганца толщиной всего 25 нм. Предположительно, двигаясь в направлении выращивания многослойных гетероструктур, а именно $\mathrm{Si}_{1-x} \mathrm{Mn}_{x} / \mathrm{Si}$, окажется возможным получить более высокие значения фактора мощности за счет сохранения высокой электропроводности вдоль интерметаллических слоев и повышения коэффициента Зеебека при увеличении числа слоев.

Работа выполнена в рамках реализации государственного задания (проекты № 8.1054.2014/К, № 3423) Министерства образования и науки России, при поддержке РФФИ (грант 15-38-20642мол_а_вед ) и гранта Президента РФ (МК-8221.2016.2).

\section{Список литературы}

[1] Е.С. Демидов, Ю.А. Данилов, В.В. Подольский, В.П. Лесников, М.В. Сапожников, А.И. Сучков. Письма ЖЭТФ, 83 (12), 664 (2006).

[2] Е.С. Демидов, В.В. Подольский, В.П. Лесников, Е.Д. Павлова, А.И. Бобров, В.В. Карзанов, Н.В. Малехонова, А.А. Тронова. Письма ЖЭТФ, 100 (11), 818 (2014).

[3] С.В. Новиков. Автореф. канд. дис. (СПб., 2014).

[4] А.В. Шевельков. (Курс лекций. Химический факультет МГУ им. М.В. Ломоносова, 2010).

[5] М.В. Дорохин, Д.А. Павлов, А.И. Бобров, Ю.А. Данилов, П.Б. Демина, Б.Н. Звонков, А.В. Здоровейщев, А.В. Кудрин, Н.В. Малехонова, Е.И. Малышева. ФТТ, 56 (10), 2062 (2014).

[6] A.F. Ioffe. Semiconductor thermoelements and thermoelectric cooling (Infosearch Ltd., London, 1957).

[7] Е.С. Демидов, Е.Д. Павлова, А.И. Бобров. Письма ЖЭТФ, 96 (11), 790 (2012).

[8] С. Зи. Физика полупроводниковых приборов (пер. с англ., 2-е перераб. и доп. изд. М., Мир, 1984) т. 1, с. 52.

[9] А.Ф. Орлов, Л.А. Балагуров, И.В. Кулеманов, Ю.Н. Пархоменко, А.В. Картавых, В.В. Сарайкин, Ю.А. Агафонов, В.И. Зиненко. ФТП, 44 (1), 30 (2010).

[10] Y.H. Kwon, T.W. Kang, C.J. Park. Sol. St. Commun., 140, 14 (2006).

[11] В.К. Зайцев, С.В. Ордин, К.А. Рахимов, А.Э. Енгалычев. ФTT, 23 (2), 621 (1981).

[12] А.А. Детлаф, Б.М. Яворский, Л.Б. Милковская. Курс физики. Т. 2. Электричество и магнетизм (М., Высш. шк., 1977) с. 376.

[13] Ф.Ю. Соломкин, В.К. Зайцев, С.В. Новиков, А.Ю. Самунин, Д.А. Пшенай-Северин, Г.Н. Исаченко. ЖТФ, 84 (8), 106 (2014).

[14] Z.-G. Chen, G. Han, L. Yang. Progr. Nat. Sci.: Mater. Internat., 22 (6), 535 (2012).

Редактор Г.А, Оганесян 


\section{$\mathrm{Si}_{1-x} \mathrm{Mn}_{x}$ thin films crystal structure and thermoelectric properties}

I.V. Erofeeva, M.V. Dorokhin, V.P. Lesnikov,

A.V. Zdoroveyshev, A.V. Kudrin, D.A. Pavlov, U.V. Usov

Research Institute for Physics and Technology by Lobachevsky State University of Nizhny Novgorod, 603950 Nizhny Novgorod, Russia

Abstract Thin $(25 \mathrm{~nm}) \mathrm{Si}_{1-x} \mathrm{Mn}_{x} / \mathrm{Si}$ (100) films were fabricated by means of the pulsed laser deposition technique. Using the high-resolution transmission electron microscopy measurements it was shown that the films are the nano-texture crystals with chemically uniform composition. The temperature dependencies of the resistivity and thermopower were measured in the range of $300-500 \mathrm{~K}$, the data was used to calculate the temperature dependence of the Seebeck coefficient and power factor. It was shown that the latter films are prospective option for the thermoelectric energy converters. 